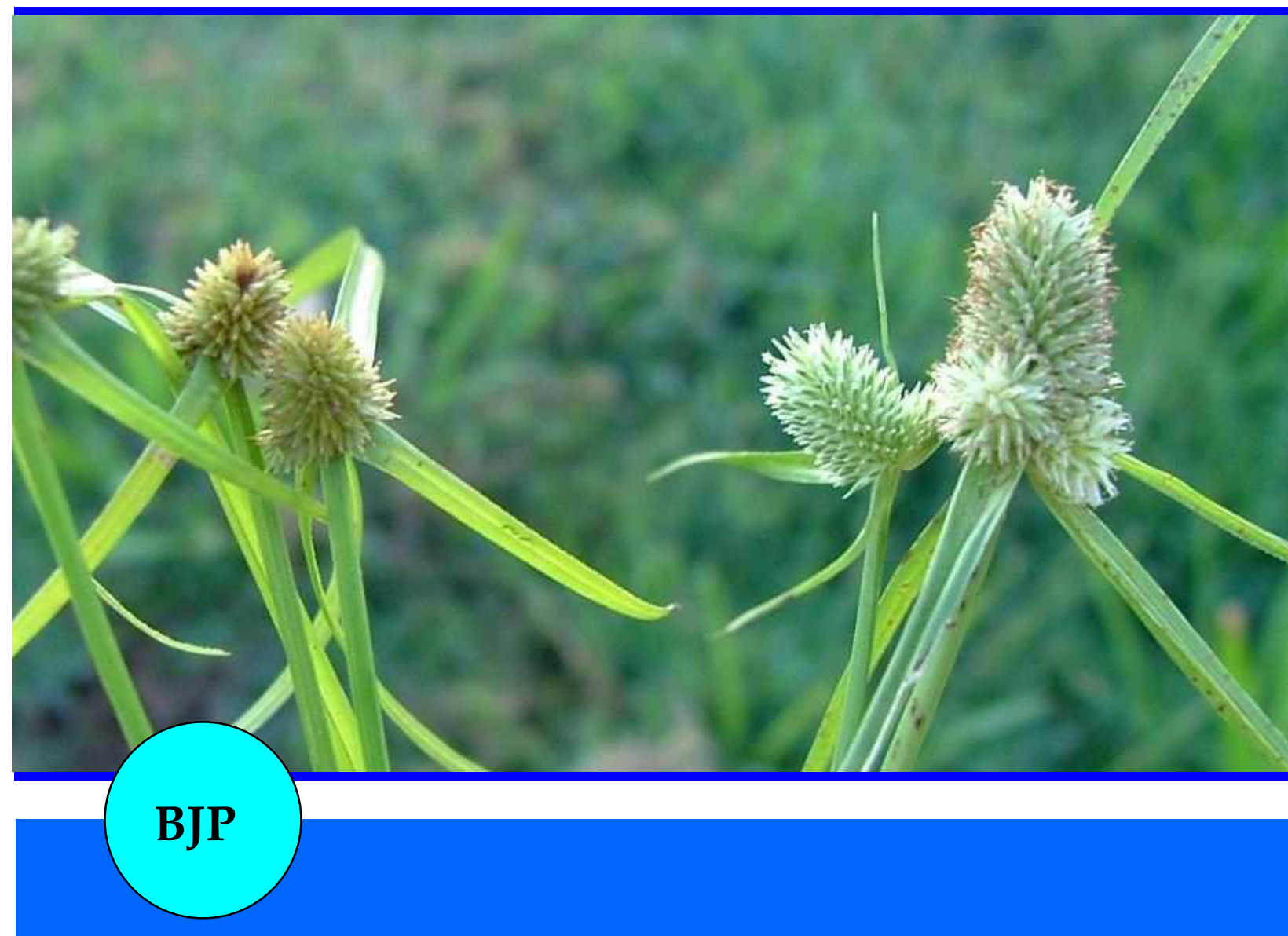

Bangladesh Journal of Pharmacology

Research Article

Antibacterial activities of endophytic fungi isolated from six Sri Lankan plants of the family Cyperaceae 


\title{
Antibacterial activities of endophytic fungi isolated from six Sri Lankan plants of the family Cyperaceae
}

\author{
Pamoda B. Ratnaweera', R. Chandula Walgama², Kinkini U. Jayasundera², Suseema D. \\ Herath', S. Abira', David E. Williams' ${ }^{3}$, Raymond J. Andersen ${ }^{3}$ and E. Dilip de Silva ${ }^{2}$ \\ ${ }^{1}$ Department of Science and Technology, Uva Wellassa University, Badulla, Sri Lanka; ${ }^{2}$ Department of Chemistry, \\ University of Colombo, Colombo 03, Sri Lanka; ${ }^{3}$ Department of Chemistry and Earth, Ocean and Atmospheric \\ Science, University of British Columbia, Vancouver, Canada.
}

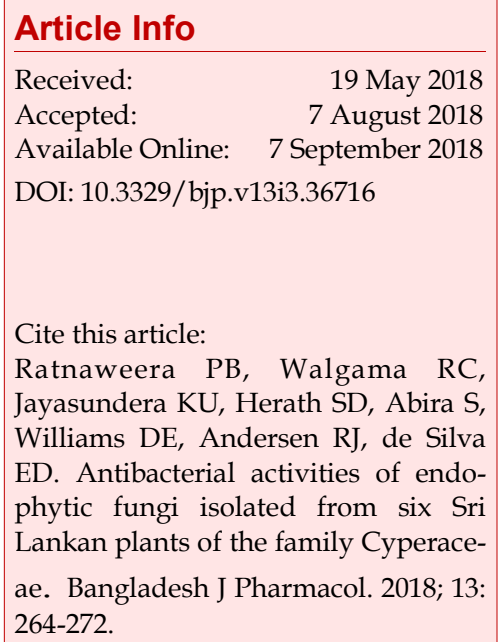

\begin{abstract}
In a study designed to determine the antibacterial potential of endophytic fungi inhabiting plants of Cyperaceae family, 72 morphologically distinct endophytic fungi were isolated from six plants and their antibacterial activities against two Gram positive and three Gram negative pathogenic bacterial species were examined. Two antibacterial metabolites from two endophytes were also isolated and their chemical structures and minimum inhibitory concentrations were determined. Sixty six fungal extracts (92\%) were active against at least one bacterium tested. Butyrolactone I isolated from the Aspergillus terreus and 9-epi viridol isolated from Trichoderma virens exhibited MIC values in the range $128-256 \mu \mathrm{g} / \mathrm{mL}$ against Gram positive Bacillus subtilits, Staphylococcus aureus, methicillin resistant S. aureus (MRSA) and Escherichia coli. Both compounds were inactive against other microorganisms tested. This study confirmed that Cyperaceae plants harbor numerous endophytes that produce antibacterial metabolites active against both Gram positive and, to a lesser extent, Gram negative bacteria.
\end{abstract}

\section{Introduction}

Notwithstanding extensive efforts towards their suppression resistant bacterial infections have persisted causing morbidity and mortality and continue to be a serious threat to the human health (Ventola, 2015a). According to the Surveillance and Control of Pathogens of Epidemiologic Importance (SCOPE) project, the number of nosocomial infections due to Gram positive bacteria have increased steadily while those due to Gram negative bacteria have remained steady (Edmond et al., 1999; Rice, 2006). Among the Gram positive pathogens, methicillin resistant Staphylococcus aureus (MRSA), drug resistant Streptococcus pneumonia (DRSP), mono to multiple drug resistant Mycobacterium tuberculosis and vancomycin resistant enterococci species play leading roles in causing infections (Sader et al., 2009;
Woodford and Livermore, 2009). Gram negative bacteria are also becoming resistant to nearly all the antibiotics available. Klebsiella penumoniae, Pseudomonas aeruginosa, Acinetobacter, Beta-lactamase-producing Escherichia coli and Neisseria gonorrhoeae are among the Gram negative bacteria which are becoming prevalent in the community causing serious infections in the bloodstream, urinary tract, surgical sites, and reproductive tract (Ventola, 2015a). If allowed to progress unimpeded consequences of resistant microbial infections are likely to be dire especially in developing countries where there are financial constraints, for the cost of therapy and availability of effective antibiotics in public-health settings (Rapp and Pharm, 1999; Okeke et al., 2005).

Averting this impending human health crisis calls for 
the speedy development of antibiotics with diverse and novel modes of action (Ventola, 2015b; Ling et al., 2015). A recent report stipulates that the antibiotics evolved from natural products can penetrate the barriers of target bacteria more successfully than the antibacterial developed from synthetic approaches (Ling et al., 2015).

Endophytic fungi inhabit the internal tissues of host plants asymptomatically. A considerable number of recent research have shown that these microorganisms, under laboratory culture conditions, produce numerous structurally diverse biologically active secondary metabolites that include antimicrobial substances (Dissanayake et al., 2016; Ratnaweera et al., 2017). Endophytic fungi are widespread and occupy virtually all plant species on Earth with their estimated number reaching a million species (Radic and Strukelj, 2012). With only a small percentage, thus, far systematically investigated these cryptic organisms represent a formidable resource that can be effectively utilized in the search for new antibiotics.

Plants of the family Cyperaceae, commonly known as sedges, show vigorous and aggressive growth regardless of environmental or ecological conditions (Hershenhorn et al., 2014). They successfully grow in harsh and disturbed environments and have the ability to flourish despite insect, microbial or pathogenic attacks (NRMMC, 2006). These considerations suggest that the endophytic fungal populations, via the production of certain specific biologically active secondary metabolites, may contribute towards the hosts' ability to overcome biotic and abiotic stresses. This hypothesis is supported by our recent isolation of the novel antibiotic solanioic acid which possesses a highly functionalized and rearranged steroidal carbon skeleton from Rhizoctonia solani which inhabits the medicinal weed Cyperus rotundus common sedge in Sri Lanka (Ratnaweera et al., 2015).

Sedges are widespread in Sri Lanka and thus become an attractive source to be investigated for their antibacterial producing potential. This paper describes the antibacterial activities of the laboratory cultures of 72 morphologically distinct endophytic fungi isolated from six Cyperaceae family plants, Cyperus brevifolius, C. melanospermus, C. alternifolius, C. bulbosus, C. rotundus, and Fimbristylis miliaceae collected from two different locations in Sri Lanka. The isolation and structure elucidation of two known antibacterial secondary metabolites, 9-epi-viridiol and butyrolactone I from two endophytic fungal cultures are also described.

\section{Materials and Methods}

\section{Plant collection and authentication}

Healthy plants of Cyperus brevifolius, C. melanosperrmus,
C. alternifolius and C. bulbosus were collected from suburban areas and paddy fields in Colombo District while C. rotundus and F. miliacea plants were collected from home gardens and paddy fields in Badulla, Sri Lanka. Colombo and Badulla are two geographically distinct areas about $210 \mathrm{~km}$ apart. Locations, where plants were collected in Colombo, were 40-50 feet above sea level with average daytime temperatures of $28-29^{\circ} \mathrm{C}$ while Badulla locations were at 2,200 feet with temperatures of $23-25^{\circ} \mathrm{C}$. One plant from each location was preserved and authenticated by the National Herbarium, Royal Botanical Gardens, Peradeniya, Sri Lanka.

\section{Isolation of endophytic fungi}

Healthy disease-free plants were brought to the laboratory within 10-24 hours of collection and were processed as follows: First, the soil, dust and dirt were removed by washing well with tap water and the plant parts were separated into aerial sections and roots. These were surface sterilized by sequentially immersing and agitating in $70 \%$ ethanol for $1 \mathrm{~min}, 5.3 \%$ sodium hypochlorite solution for $3 \mathrm{~min}$ and again in $70 \%$ ethanol for $30 \mathrm{sec}$ (Ratnaweera et al., 2016). To remove any remaining solvents, the plant parts were washed thoroughly with sterilized distilled water and air-dried inside a biosafety cabinet (BIOBASE) under aseptic conditions. Using a sterilized scalpel blade, small pieces $(1.0 \times 0.3 \mathrm{~cm})$ were cut from these surface sterilized sections and were placed on antibiotic enriched (ciprofloxacin $10 \mathrm{mg} / \mathrm{mL}$ ) potato dextrose agar, malt agar extract, malt peptone dextrose agar, starch yeast peptone agar and yeast peptone dextrose agar media dishes. To be sure that no fungi originate from the plant surface, a few drops of water from the final washing were also spread on the growth media to act as a negative control experiment. After incubation at room temperature for several days the fungi emerging from the specimen edges were transferred into new potato dextrose agar dishes (antibiotic free) and sequential sub -culturing was done until pure cultures were obtained. The colony and morphological features were used to categorize the fungi into distinct groups.

\section{Extraction of metabolites}

Each pure fungus was sub-cultured in five potato dextrose agar dishes and when the first sign of sporulation appeared, the medium with the fungus was cut into small pieces and immersed in $200 \mathrm{~mL}$ of ethyl acetate. This was left for two days and the individual extracts were filtered and evaporated to dryness under reduced pressure using a rotary evaporator (BUCHI-R200) at $40^{\circ} \mathrm{C}$ and weighed.

\section{Antibacterial bioassay of the crude fungal extracts}

All extracts were tested for antibacterial activity using a standard agar disc diffusion assay at $400 \mu \mathrm{g} /$ disc against two Gram positive bacteria, Staphylococcus aureus (ATCC 25923), Bacillus cereus (ATCC 11778), and 
two Gram negative bacteria, Pseudomonas aeruginosa (ATCC 9027), Escherichia coli (ATCC 35218) according to NCCLS standards (NCCLS, 2003). Extracts of endophytic fungi from C. brevifolius, C. melanosperrmus, $C$. bulbosus and $C$. alternifolius were also tested against Salmonella enterica (ATCC 14028). After overnight incubation, the diameter of the inhibition zone of the active extract was measured. Methanol was used as the negative control and gentamycin was used as the positive control. Each assay was run in triplicate and the mean inhibition was determined. Active extracts with more than $10 \mathrm{~mm}$ inhibition zone were tested at the two lower concentrations of 200 and $100 \mu \mathrm{g} /$ disc.

\section{Identification of the fungi}

The fungi that exhibited the highest bioactivities from each plant were identified using molecular techniques. The genomic DNA was extracted in the laboratory using a published protocol (Kariyawasam et al., 2012) while PCR amplification using universal primers ITS1 and ITS4, and DNA sequencing was carried out commercially. The gene sequences obtained were BLAST analyzed against the NCBI Genbank to determine the identities of the fungi.

\section{Large scale culturing and extraction of the selected} bioactive fungi

The bioactive fungal strains CW-CM-R6 and KU-BU-A9 were cultured in large scale on 60 and 100 potato dextrose agar petri dishes (size: $100 \times 20 \mathrm{~mm}$ ) and incubated at room temperature for 14 and 18 days respectively. After the incubation period the fungus along with the medium were cut and immersed in $750 \mathrm{~mL}$ of ethyl acetate and extracted for two days, filtered and the filtrate evaporated to dryness using a rotary evaporator at $40^{\circ} \mathrm{C}$ and the crude extracts obtained were weighed.

\section{Isolation of bioactive compounds}

\section{CW-CM-R6 extract}

The organic extract was fractionated according to a modified Kupchan method (Dissanayaka et al., 2016) detailed next. The extract (1.5 g) was first partitioned between hexane and a water/methanol (9:1) mixture. Then the aqueous layer was separated from the hexane layer, concentrated and was partitioned between chloroform and a water/methanol (6:4) mixture. Next, the chloroform layer was separated and the concentrated aqueous layer was partitioned between ethyl acetate and water. The concentration of each solvent fraction resulted in four fractions: Hexane soluble, chloroform soluble, ethyl acetate soluble, and a water soluble fraction. Since the bioactivity was prominent in the chloroform fraction $(600 \mathrm{mg}$ ) this fraction was subjected to sephadex LH-20 size exclusion column chromatography $(2.5 \times 50 \mathrm{~cm}$ column$)$ with methanol as eluent. The fractions were combined, according to the thin layer chromatography (TLC) profiles, and the bioactivity was assessed through disc diffusion assay. The most active fraction (17 mg) was further purified using normal phase silica chromato-graphy $(1 \times 20 \mathrm{~cm}$ column) with a step gradient elution from $50 \%$ ethyl acetate/hexane to ethyl acetate. The bioactive fraction, eluting with $50 \%$ ethyl acetate/hexane, was determined to be compound 1 .

\section{KU-BU-A9 extract}

The crude extract of KU-BU-A9 was also first fractionated by solvent-solvent partitioning using the same procedure described above for extract CW-CM-R6. The bioassay results for the four fractions, hexane, chloroform, ethyl acetate and water, revealed that the chloroform was active. The active chloroform fraction was then subjected to a normal phase silica chromatography (column size: $40 \times 3.5 \mathrm{~cm}$ ), using gradient elution from $27 \%$ ethyl acetate:hexane to methanol. The resulting fractions collected were combined according to their TLC profiles and bioactivity was monitored using a TLC bioautography. A second normal phase silica chromatography (column size: $30 \times 3 \mathrm{~cm}$ ) using gradient elution ( $25 \%$ hexane: ethyl acetate to methanol) was followed by high performance liquid chromatography (HPLC) using a $\mathrm{C}_{18}$ Inert Sustain, $5 \mu \mathrm{m}, 25 \times 1$ $\mathrm{cm}$ column with 45:55 $\mathrm{H}_{2} \mathrm{O} / \mathrm{MeCN}$ as eluent to give compound 2 with a retention time of $55 \mathrm{~min}$.

\section{Structure elucidation of the isolated active compounds}

The chemical structures of the purified active compounds were elucidated using ESIMS and 1D and 2D NMR spectral analysis. ${ }^{1} \mathrm{H},{ }^{13} \mathrm{C}$ and $2 \mathrm{D}$ NMR data sets in DMSO- $d_{6}$ were obtained using a Bruker AVANCE $600-\mathrm{MHz}$ spectrometer with a $5 \mathrm{~mm}$ cryoprobe, while the electrospray ionization mass spectral (ESIMS) data were obtained using a Bruker Esquire-LC electrospray spectrometer.

\section{Antimicrobial activity of the isolated pure compounds}

A minimum inhibitory concentration (MIC) assay was performed against four Gram positive bacteria, $B$. subtilis (UBC 344), S. aureus (ATCC 43300), Enterococcus faecalis (ATCC 51575) and MRSA (ATCC 33591), four Gram negative bacteria E. coli (UBC 1861), P. aeruginosa (ATCC 27853), Acinetobacter johnsonii (ATCC 17909) and Klebsiella pneumonia (ATCC 13883) and the pathogenic fungus Candida albicans (ATCC 90028) using a broth micro dilution method according to the NCCLS standards with modification using Mueller Hinton broth as the medium (NCCLS, 2002). Assay was conducted in triplicate and the mean values were used to calculate the MIC. The MIC endpoint was taken as the lowest concentration with more than $90 \%$ bacterial growth inhibition. DTX 880 (Beckman Coulter Inc.) plate reader was used to determine the optical density of the bacterial growth. The commercial antimicrobial 


\begin{tabular}{|c|c|c|c|}
\hline \multicolumn{4}{|c|}{ Table I } \\
\hline \multicolumn{4}{|c|}{$\begin{array}{c}\text { Number of isolated endophytic fungi from C. brevifolius, C. melanosperrmus, C. alternifolius, C.bulbosus, } \\
\text { C. rotundus and F. miliaceae }\end{array}$} \\
\hline \multirow[t]{2}{*}{ Plant species } & \multicolumn{3}{|c|}{ Number of isolated endophytic fungi from each plant } \\
\hline & Total number of distinct isolates & Isolates from aerial parts & Isolates from roots \\
\hline C. brevifolius & 10 & 03 & 07 \\
\hline C. melanosperrmus & 18 & 12 & 06 \\
\hline C. alternifolius & 10 & 01 & 09 \\
\hline C. bulbosus & 11 & 06 & 05 \\
\hline C. rotundus & 13 & 05 & 08 \\
\hline F. miliaceae & 10 & 06 & 04 \\
\hline
\end{tabular}

agents polymyxin B for B. subtilis, E. coli, P. aeruginosa, E. faecalis, A. johnsonii and K. pneumonia, rifamycin for $S$. aureus, and MRSA, and nystatin for C. albicans were used as positive controls with a concentration series of 2.0-0.004 $\mu \mathrm{g} / \mathrm{mL}$.

\section{Results \\ Endophytic fungal richness in the Cyperaceae plants species}

The total numbers of fungi isolated from each of the selected Cyperaceae plants, together with the numbers isolated from the aerial and root sections are mentioned in Table I. In total, 72 morphologically distinct fungi were isolated from the six Cyperaceae family plants. In comparing the numbers of endophytes isolated from aerial parts and the roots, 39 endophytes were isolated from roots while 33 have originated from the aerial parts.

\section{Antimicrobial activities of the isolated endophytic fungi}

Table II and III show the antibacterial activities exhibited by the 72 endophytic fungal crude extracts against the tested bacteria at $400 \mu \mathrm{g} /$ disc concentration. Among them, $91.6 \%$ of extracts were active against at least one bacterium tested. Further, 28 endophytic fungal extracts showed activity only against Gram positive bacteria, while nine were active solely against Gram negative bacteria. Six extracts showed no activity against the bacteria tested and none of the extracts showed activity against all the bacteria tested. Out of the endophytic fungal crude extracts $75 \%$ showed activity against $S$. aureus, $61 \%$ against B. cereus, $40 \%$ against $P$. aeruginosa, 33\% against E. coli and 14\% against $S$. enterica.

According to Table II all the endophytic fungi isolated from C. brevifolius were active against Gram positive bacteria, while $89 \%$ of endophytic fungi from $C$. melanosperrmus have exhibited activity against $S$. aureus and $100 \%$ against B. cereus. No activity was observed against $P$. aeruginosa by any of the fungi from $C$. brevifolius and C. meanospermus. Additionally, none of the endophytic fungal extracts from C. brevifolius were active against $S$. enterica while three, one and three endophytic fungi from C. melanospermus, C. bulbosus and $C$. alternifolius, respectively show modest activity against $S$. enterica.

In contrast to the activity of endophytic fungi from Cyperaceae plants from Colombo, endophytic fungi collected from Badulla plants exhibit more activity towards Gram negative bacteria. According to Table III, $87 \%$ endophytic fungal extracts show activity against $P$. aeruginosa while $56 \%$ have activity against $E$. coli, while $65 \%$ show activity against the Gram positive S. aureus as well.

The extracts with zones of inhibition of more than 10 $\mathrm{mm}$ at $400 \mu \mathrm{g} /$ disc were screened at lower concentrations. At $100 \mu \mathrm{g} /$ disc, four extracts each from $C$. brevifolius (CW-CB-R2, CW-CB-R5, CW-CB-R7, CW-CBR10), C. melanosperrmus (CW-CM-R6, CW-CM-A6, CWCM-R10, CW-CM-A12) and C. rotundus (SH-CR-R1, SHCR-R3, SH-CR-R8, SH-CR-R9), three extracts each from C. bulbosus (KU-BU-R1, KU-BU-R6, KU-BU-9L) and C. alternifolius (KU-ALT-R3, KU-ALT-R5, KU-ALT-10R), and two extracts from F. miliaceae (SA-FM-R4, SA-FMR6) exhibited activity.

\section{Identification of endophytic fungi}

The two bioactive endophytic fungi selected for further studies were identified using molecular techniques. When the sequences obtained were BLAST analyzed against the NCBI Genbank database CW-CM-R6 and KU-BU-A9, identities were received as Trichoderma virens and Aspergillus terreus, respectively.

\section{Isolation and structure elucidation of the antibacterial metabolites}

Solvent-solvent partitioning of the CW-CM-R6 crude extract $(1.5 \mathrm{~g})$ followed by size exclusion and normal phase silica chromatography led to the isolation of the active compound 1 which gave a $[\mathrm{M}+\mathrm{Na}]^{+}$ion at $\mathrm{m} / \mathrm{z}$ 377 in the low-resolution electrospray ionization mass 


\section{Table II}

\section{Antibacterial activities of the crudes extracts of endophytic fungi from $C$. brevifolius, $C$. melanosperrmus,} C. alternifolius, C. bulbosus at $400 \mu \mathrm{g} / \mathrm{disc}$ concentration

\begin{tabular}{|c|c|c|c|c|c|}
\hline \multirow[t]{2}{*}{ Fungal identification code } & \multicolumn{5}{|c|}{ Mean diameter of the inhibition zone in $\mathrm{mm}$} \\
\hline & S. aureus & B. cereus & S. enterica & E. coli & P. aeruginosa \\
\hline CW-CB-A2 & 12 & 14 & - & - & - \\
\hline CW-CB-A5 & 11 & 12 & - & 09 & - \\
\hline CW-CB-A6 & 11 & 22 & - & - & - \\
\hline CW-CB-R2 & 25 & 26 & - & - & - \\
\hline CW-CB-R3 & 08 & 10 & - & - & - \\
\hline CW-CB-R4 & 13 & 14 & - & - & - \\
\hline CW-CB-R5 & 21 & 18 & - & - & - \\
\hline CW-CB-R7 & 14 & 24 & - & 09 & - \\
\hline CW-CB-R8 & 10 & 08 & - & - & - \\
\hline CW-CB-R10 & 18 & 15 & - & - & - \\
\hline CW-CM-A2 & 15 & 08 & - & 09 & - \\
\hline CW-CM-A3 & 08 & 10 & - & - & - \\
\hline CW-CM-A4 & 09 & 15 & - & - & - \\
\hline CW-CM-A5 & 08 & 08 & - & - & - \\
\hline CW-CM-A6 & 18 & 22 & 11 & 15 & - \\
\hline CW-CM-A7 & 10 & 12 & - & - & - \\
\hline CW-CM-A8 & 10 & 09 & - & - & - \\
\hline CW-CM-A9 & 08 & 18 & - & 10 & - \\
\hline CW-CM-A10 & - & 09 & - & - & - \\
\hline CW-CM-A11 & - & 16 & - & - & - \\
\hline CW-CM-A12 & 11 & 22 & 11 & 10 & - \\
\hline CW-CM-A15 & 09 & 30 & - & - & - \\
\hline CW-CM-R1 & 08 & 08 & - & - & - \\
\hline CW-CM-R3 & 14 & 15 & - & - & - \\
\hline CW-CM-R5 & 10 & 20 & - & - & - \\
\hline CW-CM-R6 & 22 & 15 & 21 & - & - \\
\hline CW-CM-R8 & 11 & 08 & - & - & - \\
\hline CW-CM-R10 & 25 & 28 & - & - & - \\
\hline KU-BU-R1 & 21.5 & 35 & - & 11 & 13 \\
\hline KU-BU-A2 & - & - & - & - & 8 \\
\hline KU-BU-A4 & - & - & - & - & - \\
\hline KU-BU-A5 & - & - & - & - & - \\
\hline KU-BU-R6 & 13.5 & 14 & - & - & 7 \\
\hline KU-BU-A7 & - & - & - & - & - \\
\hline KU-BU-R8 & 10 & 11 & - & - & - \\
\hline KU-BU-A9 & 15 & 15 & - & 9 & - \\
\hline KU-BU-R11 & 10 & 11 & - & - & - \\
\hline KU-BU-R12 & - & 9 & - & - & - \\
\hline KU-BU-A14 & - & - & 10 & 9 & 7 \\
\hline KU-ALT-R1 & - & - & - & - & - \\
\hline KU-ALT-R2 & 10 & - & 9.5 & 13 & 12 \\
\hline KU-ALT-R3 & - & - & 12 & 15.5 & 9 \\
\hline KU-ALT-R4 & 9 & - & 8 & - & 10 \\
\hline KU-ALT-R5 & 20 & 25 & - & - & - \\
\hline KU-ALT-R6 & - & - & - & - & - \\
\hline KU-ALT-R7 & 9 & 15 & - & - & - \\
\hline KU-ALT-A8 & - & - & - & - & 12 \\
\hline KU-ALT-R9 & 7.5 & 13 & - & - & - \\
\hline KU-ALT-R10 & 9.5 & 20 & - & - & 7 \\
\hline$+\mathrm{Ve}$ & 21 & 25 & 20 & 20 & 25 \\
\hline$+\mathrm{Ve}$ & - & - & - & - & - \\
\hline
\end{tabular}


Table III

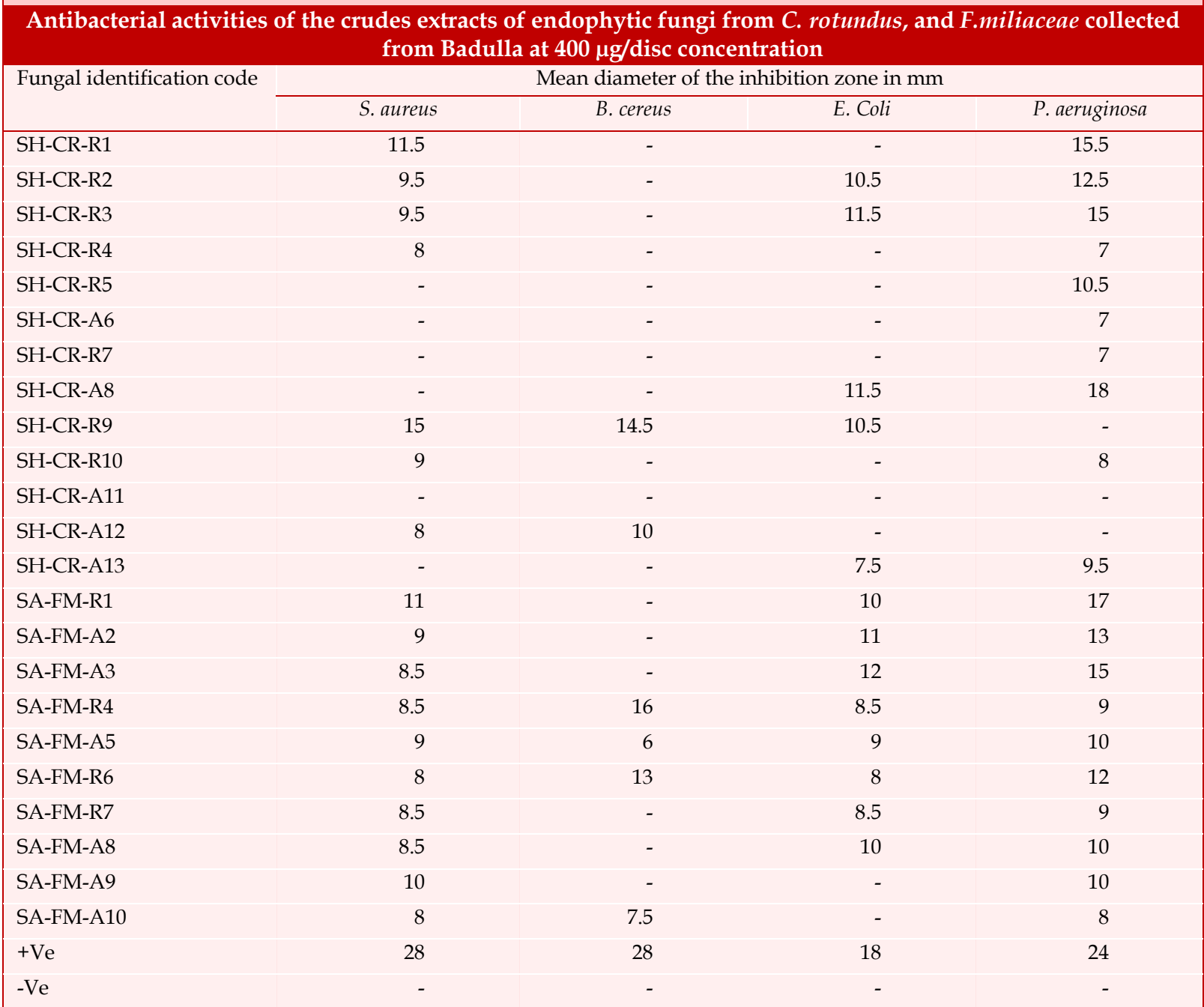

spectrum (LRESIMS) which is consistent with a molecular weight of 354 daltons and a molecular formula of $\mathrm{C}_{20} \mathrm{H}_{18} \mathrm{O}_{6}$. Analysis of ${ }^{1} \mathrm{H},{ }^{13} \mathrm{C}$ and $2 \mathrm{D}$ (COSY, HSQC, HMBC, TROESY) NMR spectral data run in DMSO- $d_{6}$ revealed that the structure of the active compound 1 (Figure 1) matches the known furanosteroid, 9-epi-viridol (Phuwapraisirisan et al., 2006).

Bioassay-guided isolation of the ethyl acetate crude extract $(650 \mathrm{mg})$ of KU-BU-9L led to the active compound 2 (Figure 1) which gave a $[\mathrm{M}+\mathrm{Na}]^{+}$ion in the LRESIMS at m/z 447 appropriate for a molecular weight of 424 daltons and a molecular formula of $\mathrm{C}_{24} \mathrm{H}_{24} \mathrm{O}_{7}$. Analysis of ${ }^{1} \mathrm{H}$ and ${ }^{13} \mathrm{C}$ NMR data as well as 2D NMR (COSY, HSQC, HMBC, tROESY) spectral data in $\mathrm{DMSO}-d_{6}$ revealed that the structure of the active compound (2) matches that of butyrolactone I (Rao et al., 2000).

Antimicrobial activity of butyrolactone I and 9-epiviridol
In the present study, 9-epi viridol (1) gave MIC values of $256 \mu \mathrm{g} / \mathrm{mL}$ against B. subtilis, S. aureus, MRSA and E. coli. Butyrolactone I (2) exhibited activities against Gram positive B. subtilits with a MIC of $128 \mu \mathrm{g} / \mathrm{mL}$, and S. aureus, MRSA and E. coli with MIC's of $256 \mu \mathrm{g} / \mathrm{mL}$.

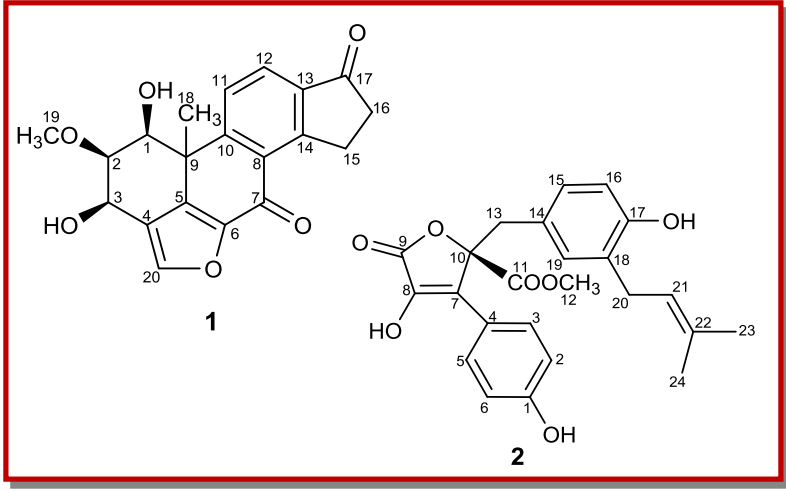

Figure 1: Chemical structures of 9-epi-viridol (1) and Butyrolactone I (2) 
At $256 \mu \mathrm{g} / \mathrm{mL}$ both compounds were inactive against the other bacteria and C. albicans tested.

\section{Discussion}

According to the results of the current study, endophytic fungi show a high species richness in each Cyperaceae plant species indicating that Cyperaceae family plants are good reservoirs for endophytic fungi. In three plants the majorities of endophytes have come from the roots while in the other three majority were from aerial parts and this suggests that there is no obvious preference of endophytes for either location. Plant tissues are reservoirs not only for fungi but bacteria as well. Thus, in the initial isolation of the endophytic fungi, an antibiotic was incorporated into the culture media to inhibit the growth of endophytic bacteria. This was a preventive measure to thwart the potentially rapid growth of endophytic bacteria that might restrict fungal growth and so make the isolation of the endophytic fungi difficult. The numbers of endophytic fungi inhabiting a specific host plant may vary from a few species to a large number, for example nearly 100 species (Tanvir et al., 2017). Some such species may be quite fastidious in their nutrient requirements making their isolation challenging or even impossible. Since different fungi prefer different nutrient conditions for growth, to maximize the number of fungal species isolated in this study in addition to potato dextrose agar, four different nutrient media, starch yeast peptone agar, malt agar extract, malt peptone dextrose agar and yeast peptone dextrose agar were used. In addition, the use of a number of different growth media may provide favorable conditions for slow-growing fungi by inhibiting fast growing competitive fungi (Ratnaweera et al., 2015).

Display of antibacterial activity by more than $90 \%$ out of the isolated endophytic fungi suggests that most endophytic fungi of Cyperacae plants are potential synthesizers of antibacterial secondary metabolites. Further according to the results, more extracts were active against the Gram positive bacteria than the Gram negative. The contrasting activity against Gram negative bacteria shown by the endophytic fungi of Cyperaceae plants from Badulla area, is likely due to the difference of metabolites produced by the fungi. However, at this point, we cannot predict whether the difference in the metabolites is due to a difference in the host plants or due to the different environmental and climatic conditions at the two locations.

Previously furanosteroid (1) was reported to have been isolated from a soil inhabiting $T$. virens (Phuwapraisirisan et al., 2006). In the current study, compound 1 was isolated from the endophytic form of T. virens. Likewise, butyrolactone I (2) has been isolated previously from the same fungus, $A$. terreus, as in this study as well as from A. versicolor (Nuclear et al., 2010; Shen et al., 2012; Chen et al., 2015a; Zhou et al., 2015; Guo et al., 2016). A. terreus has been isolated from a variety of substrates that embrace soils, marine organisms (such as a Gorgonian sp.), mangrove associated sediments, and in its endophytic form from various plants other than sedges (Nuclear et al., 2010; Awaad et al., 2012; Shen et al., 2012; Nong et al., 2014; Chen et al., 2015a; Chen et al., 2015b; Zhou et al., 2015; Guo et al., 2016;). A. terreus is a prolific producer of secondary metabolites. Among the metabolites isolated from A. terreus are lovastatin, citrinin, aspulvinone, asterric acid, rollini, emodin, questrin, asterriquinone, itaconate and terrecyclic acid (Awaad et al., 2012).

Compound 1 has previously been reported as cytotoxic against KB (human epidermoidcarconoma, IC $\mathrm{IC}_{50} 19 \mu \mathrm{g} /$ $\mathrm{mL}$ ) and HeLa (human cervical carcinoma $\mathrm{IC}_{50} 50 \mathrm{\mu g} /$ $\mathrm{mL}$ ) cell lines and as both a fungistatic (viridin) and herbicidal (viridol) agent (Brian and McGowan, 1945; Jones and Hancock, 1987; Jones et al., 1988; Phuwapraisirisan et al., 2006). To the best of our knowledge, this is the first time that the antimicrobial activities of 9epi-viridol have been reported. In previous studies compound $\mathbf{2}$ has exhibited moderate anti-inflammatory activity, mild cytotoxic activity against a number of cell lines, antifungal activity and weak to moderate antibacterial activity against Gram positive bacteria (Muhammad et al., 2004; Nong et al., 2014; Chen et al., 2015a; Zhou et al., 2015).

As far as we are aware, this is the first broad study of the antimicrobial activities of the endophytic fungi of Cyperaceae family plants. The results reveal that Cyperaceae family plants are hosts to numerous endophytic fungi with a broad spectrum of antimicrobial activities against Gram negative and Gram positive bacteria.

Overall the majority of the fungal extracts examined exhibited antimicrobial activities against Gram positive bacteria with a smaller number active against Gram negative organisms. These findings suggest that the endophytic fungi of Cyperaceae plants are a potential source that can be utilized in the search for new antibiotics against both Gram positive and Gram negative bacteria. In the current study, the two antimicrobial compounds isolated turned out to be known fungal metabolites. Therefore, to realize the full potential of these endophytes, additional investigation of the remaining active extracts is needed.

\section{Acknowledgement}

This work was partially supported by the National Science Foundation Research Grant (RG/2016/EB/03), Sri Lanka. 


\section{Conflict of Interest}

The authors declare that they have no competing interests.

\section{References}

Awaad AS, Nabilah AA, Zain ME. New antifungal compounds from Aspergillus terreus isolated from desert soil. Phytother Res. 2012; 226: 1872-77.

Brian PW, McGowan JC. Viridin: A highly fungistatic substance produced by Trichoderma viride. Nature 1945; 156: 144-45.

Chen H, Daletos G, Abdel-Aziz M, Thomy D, Dai H, BrotzOesterhelt H, Lin W, Proksch P. Inducing secondary metabolites production by the soil-dwelling fungus Aspergillus terreus through bacterial co-culture. Phytochem Lett. 2015a; 12: 35-41.

Chen M, Wang KL, Liu M, She ZG, Wang CY. Bioactive steroid derivatives and butyrolactone derivatives from a Gorgonianderived Aspergillus sp. Fungus. Chem Biodivers. 2015b; 12: $1398-406$

Dissanayake RK, Ratnaweera PB, Williams DE, Wijayarathne CD, Wijesundera RLC, Andersen RJ, de Silva ED. Antimicrobial activities of mycoleptodiscin B isolated from endophytic fungus Mycoleptodiscus sp. of Calamus thwaitesii Becc. J Appl Pharm Sci. 2016; 6: 1-6.

Edmond MB, Wallace SE, McClish DK, Pfaller MA, Jones RN, Wenzel RP. Nosocomial bloodstream infections in United States hospitals: A 3-year analysis. Clin Infect Dis. 1999; 29: $239-44$.

Guo F, Li Z, Xu X, Wang K, Shao M, Zhao F, Wang H, Hua H, Pei Y, Bai J. Butenolide derivatives from the plant endophytic fungus Aspergillus terreus. Fitoterapia 2016; 113: 44-50.

Hershenhorn J, Zion B, Smirnov E, Weissblum A, Shamir N, Dor E, Achdari G, Ziadna H, Shilo A. Cyperus rotundus control using a mechanical digger and solar radiation. Weed Res. 2014; 55: 42-50.

Jones RW, Hancock JG. Conversion of viridian to viridol by viridian-producing fungi. Canadian J Microbiol. 1987; 33: 963 $-66$.

Jones RW, Lanini WT, Hancock JG. Plant growth response to the phytotoxin viridol produced by the fungus Gliocladium virens. Weed Sci. 1988; 36: 683-87.

Kariyawasam GK, Mithrasena YJPK, Fernando THPS, Wijesundera RLC, Wijesundera WSS. A new cost effective method for extracting genomic DNA from fungi. Abstracts of Papers, 5th Annual Sessions of Institute of Biochemistry, Molecular Biology and Biotechnology, volume 5, Institute of Biochemistry, Molecular Biology and Biotechnology, Colombo, April 27, 2012; pp 49.

Ling LL, Schneider T, Peoples AJ, Spoering AL, Engels I, Conlon BP, Mueller A, Schaberle TF, Hughes DE, Epstein S, Jones M, Lazarides L, Steadman VA, Cohen DR, Felix CR, Fetterman KA, Millett WP, Nitti AG, Zullo AM, Chen C, Lewis KA. New antibiotic kills pathogens without detectable resistance. Nature 2015; 517: 455-59.
Muhammad I, Choudhary SG, Musharraf TM, Farzana S, Shamsher A, Atta-ur R. Isolation of bioactive compounds from Aspergillus terreus. Z Naturforsch. 2004; 59b: 324-28.

National Committee for Clinical Laboratory Standards (NCCLS). Performance Standards for Antimicrobial Susceptibility Tests, Approved Standard, document M2-A8. $8^{\text {th }}$ edition. National Committee for Clinical Laboratory Standards, Clinical and Laboratory Standards Institute, Wayne, USA, 2003.

National Committee for Clinical Laboratory Standards (NCCLS). Performance Standards for Antimicrobial Susceptibility Testing: Twelfth Information Supplement, M100-S12. National Committee for Clinical Laboratory Standards, Clinical and Laboratory Standards Institute, Wayne, USA, 2002

Natural Resource Management Ministerial Council (NRMMC). Australian Weeds Strategy - A national strategy for weed management in Australia. Australian Government Department of the Environment and Water Resources, Canberra, 2006.

Nong XH, Wang YF, Zhang XY, Zhou MP, Xu XY, Qi SH. Territrem and Butyrolactone derivatives from a marinederived fungus Aspergillus terreus. Mar Drugs. 2014; 12: 611324

Nuclear P, Sommit D, Boonyuen N, Pidhom K. Butenolide and furandione from an endophytic Aspergillus terreus. Chem Pharm Bull. 2010; 58: 1221-23.

Okeke IN, Laxminarayan R, Bhutta ZA, Duse AG, Jenkins P, O'Brien TF, Pablos-Mendez A, Klugman KP. Antimicrobial resistance in developing countries. Part 1: Recent trends and current status. Lancet Infect Dis. 2005; 5: 481-93.

Phuwapraisirisan P, Rangsaan J, Siripong P, Tip-Pyang S. 9-epi -Viridiol, a novel cytotoxic furanosteroid from soil fungus Trichoderma virens. Nat Prod Res. 2006; 20: 1321-25.

Radic N, Strukelj B. Endophytic fungi-The treasure chest of antibacterial substances. Phytomedicine 2012; 19: 1270-84.

Rao KV, Sadhukhan AK, Veerender M, Ravikumar V, Mohan EVS, Dhanvantri SD, Sitaramkumar M, Moses Babu J, Vyas K, Om Reddy G. Butyrolactones from Aspergillus terreus. Chem Pharm Bull. 2000; 48: 559-62.

Rapp RP, Pharm D. Antimicrobial resistance in Gram-positive bacteria: The myth of the MIC. Pharmacotherapy 1999; 19: 112S-9S.

Ratnaweera PB, de Silva ED. Endophytic fungi: A remarkable source of biologically active secondary metabolites. In: Endophytes: Crop productivity and protection. Sustainable development and biodiversity. Maheshwari D, Annapurna K. (eds). Vol 16. Springer, Cham, 2017, pp 191-212.

Ratnaweera PB, de Silva ED, Wijesundera RLC, Andersen RJ. Antimicrobial constituents of Hypocrea virens, an endophyte of the mangrove-associate plant Premna serratifolia L. J Natn Sci Foundation Sri Lanka, 2016; 44: 43-51.

Ratnaweera PB, de Silva ED, Williams DE, Andersen RJ. Antimicrobial activities of endophytic fungi obtained from the arid zone invasive plant Opuntia dillenii and the isolation of equisetin, from endophytic Fusarium sp. BMC Complem Altern M. 2015; 15: 220. 
Ratnaweera PB, Williams DE, Patric BO, de Silva ED, Andersen RJ. Solanioic acid, an antibacterial degraded steroid produced in culture by the fungus Rhizoctonia solani isolated from tubers of the medicinal plant Cyperus rotundus. Org Lett. 2015; 17: 2074-77.

Rice LB. Antimicrobial resistance in Gram-positive bacteria. AM J Med. 2006; 119: S11-19.

Sader HS, Moet GJ, Jones RN. Antimicrobial resistance among Gram-positive bacteria isolated in Latin American Hospitals. J Chemother. 2009; 21: 611-20.

Shen Y, Zou J, Xie D, Ge H, Cao X, Dai J. Butyrolactone an Cycloheptanetrione from mangrove-associated fungus Aspergillus terreus. Chem Pharm Bull. 2012; 60: 1437-41.

Tanvir R, Javeed A, Bajwa AG. Endophyte bioprospecting in
South Asian medicinal plants: An attractive resource for biopharmaceuticals. Appl Microbiol Biot. 2017; 101: 1831-44.

Ventola CL. The antibiotic resistance crisis. Part 1: Causes and threats. Pharm Ther. 2015a; 40: 277-83.

Ventola CL. The antibiotic resistance crisis: Part 2: Management strategies and new agents. Pharm Ther. 2015b; 40: 34452.

Woodford N, Livermore DM. Infections caused by Grampositive bacteria: A review of the global challenge. J infect. 2009; 59: S4-16.

Zhou M, Du G, Yang HY, Xia CF, Yang JX, Ye Y, Gao XM, Li $\mathrm{XN}, \mathrm{Hu} \mathrm{QF}$. Antiviral butyrolactones from the endophytic fungus Aspergillus versicolor. Planta Med. 2015; 81: 235-40. 